\title{
The formation of a metallacycloheptadienyl intermediate in the reaction of palladacyclopentadienyl derivatives with tetracyanoethylene
}

\author{
Luciano Canovese *, Fabiano Visentin, Claudio Santo \\ Dipartimento di Chimica, Università C' Foscari, Calle Larga S. Marta 2137, 30123 Venezia, Italy
}

Received 15 May 2007; received in revised form 11 June 2007; accepted 11 June 2007

Available online 29 June 2007

\begin{abstract}
The palladium(II) derivatives of the type $1\left[\mathrm{Pd}\left(\mathrm{LL}^{\prime}\right)\left(\mathrm{C}_{4} \mathrm{R}_{1} \mathrm{R}_{2} \mathrm{R}_{3} \mathrm{R}_{4}\right)\right]\left(\mathrm{LL}^{\prime}=\mathrm{HNSPh}\right.$ 2-(phenylthiomethyl)-pyridine (A), BiPy: 2,2'bipyridyl (B), DPPE: bis-diphenylphosphinoethane (C), NEOC: neocuproine (2,2'-dimethyl-o-phenanthroline) (D), $\mathrm{R}_{1}=\mathrm{R}_{4}=\mathrm{COOMe}$, $\mathrm{R}_{2}, \mathrm{R}_{3}=\mathrm{C}_{10} \mathrm{H}_{6}(\mathbf{a}), \mathrm{R}_{1}=\mathrm{R}_{3}=\mathrm{C}_{6} \mathrm{H}_{5}, \mathrm{R}_{2}=\mathrm{R}_{4}=$ COOMe (b), $\mathrm{R}_{1}=\mathrm{R}_{2}=\mathrm{R}_{3}=\mathrm{R}_{4}=$ COOMe (c)) react with the electron poor olefin tetracyanoethylene (TCNE) to yield under mild conditions the type 2 cycles $C_{6}(C N)_{4} R_{1} R_{2} R_{3} R_{4}$ and the corresponding palladium $(0)$ olefin derivative $\left.\left[\operatorname{Pd}\left(\eta^{2}\right]-T C N E\right)\left(L^{\prime}\right)\right]$. The olefin insertion reactions are usually fast, but in the case of the reaction of complex 1Da with TCNE accumulation of an intermediate is observed. The low temperature NOESY spectrum allows the determination of the intermediate structure which can be described as a hepta-membered metallacycle species.
\end{abstract}

(c) 2007 Elsevier B.V. All rights reserved.

Keywords: Fluoroanthene-like cycles; Palladacyclopentadienyl complexes; Tetracyanoethylene; Metallacycloheptadiene

We have recently studied the oxidative coupling of activated alkynes with palladium $(0)$ olefin derivatives and the related mechanism of formation of a palladium(II) metallacycle which represents a key intermediate in the palladium mediated reactions involving unsaturated molecules [1]. Subsequently, we have investigated the formation under mild conditions of fluoroanthene-like cycles obtained by the reductive elimination of the metal from the palladium(II) metallacycle derivative promoted by the formation of a stable palladium( 0 ) olefin complex and/or by the aromatization of the cycle itself (Scheme 1) [2].

In an attempt at establishing the intimate mechanism governing the olefin attack on the palladacycle species we have planned this new set of investigations in the awareness that this kind of reaction would arouse remarkable interest among scientists, as is witnessed by the relevant number of papers published in recent years dealing with oligomeriza-

\footnotetext{
${ }^{*}$ Corresponding author. Tel.: +39041 2348571; fax: +39041 2348517 .

E-mail address: cano@unive.it (L. Canovese).
}

tion and annulation reactions [3]. It is noteworthy that apart from some theoretical studies on $\mathrm{Pd} / \mathrm{MgO}$ acetylene heterogeneous cyclotrimerization, no structures of the intermediate formed by the palladium cyclometallate and the entering unsaturated molecule are proposed in the literature [4]. The palladium based catalysts, while representing the first choice in the benzannulation of enynes, do not display the same remarkable reactivity when other unsaturated hydrocarbons are involved [5]. Usually, a number of different metals are used for that purpose and papers dealing with intermediates containing $\mathrm{Rh}, \mathrm{Ti}, \mathrm{Co}, \mathrm{Cu}$ and Ir are quite common in the literature [6]. Two different intermediates are involved in these kinds of reactions, namely the Diels-Alder (A) and the metallacycloheptadiene adduct (B) (Chart 1).

Since both species are theoretically possible we have prepared some suitable palladacyclic complexes whose structure and reactivity would allow the determination of the nature of the intermediate. In this respect we have synthesized the complexes reported in Scheme 2. 


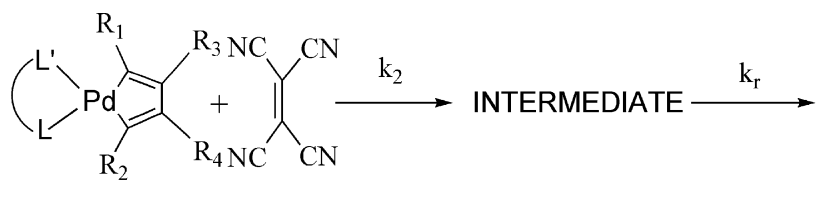

1

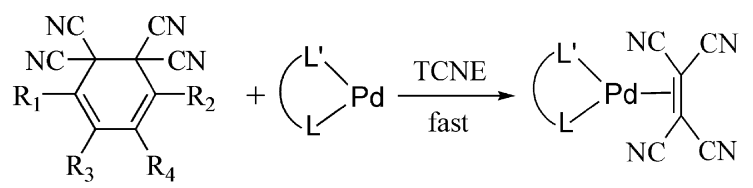

$\mathbf{2 a}, \mathbf{2 b}, \mathbf{2 c}$

3A, 3B, 3C, 3D

Chart 2.

Table 1

Rate constants for the reactions of the complexes $1 \mathrm{Ac}, \mathbf{1 B c}$ and 1Da with TCNE in $\mathrm{CHCl}_{3}$ at $298 \mathrm{~K}$

\begin{tabular}{lll}
\hline Complex & $k_{2}\left(\mathrm{~mol}^{-1} \mathrm{dm}^{3} \mathrm{~s}^{-1}\right)$ & $k_{r}\left(\mathrm{~s}^{-1}\right)$ \\
\hline $\mathbf{1 A c}$ & $20 \pm 1$ & Fast \\
1Bc & $5.6 \pm 0.1$ & Fast \\
1Da & $3.0 \pm 0.1$ & $0.030 \pm 0.001$ \\
\hline
\end{tabular}

stages which are treated as two consecutive reactions. The first stage again linearly depends on TCNE concentration while the second one is concentration independent $\left(k_{r}\right)$.

In Fig. 1 the linear regressions of the rate constants related to the first stage for all the studied complexes are reported.

Analysis of the rate constants in Table 1 seems to indicate that the steric and electronic interplay between ligand and palladacyclic ring strongly influences the reaction path. Thus, the electron withdrawal from palladium promoted by four carbomethoxy groups slows down the rate of the first attack of the activated olefin. The second order rate constant becomes in these cases accessible and the HNSPh complex displays an enhanced reactivity with respect to the BiPy derivative (3.6:1). No information can however be deduced about the intermediate structure owing to its instability and its subsequent fast decay. Apparently, the metal centre of the $\mathbf{1 A a}-\mathbf{1 C b}$ species which are characterized by a palladacycle containing carbomethoxy and phenyl (or naphthyl) groups, maintains an electron density

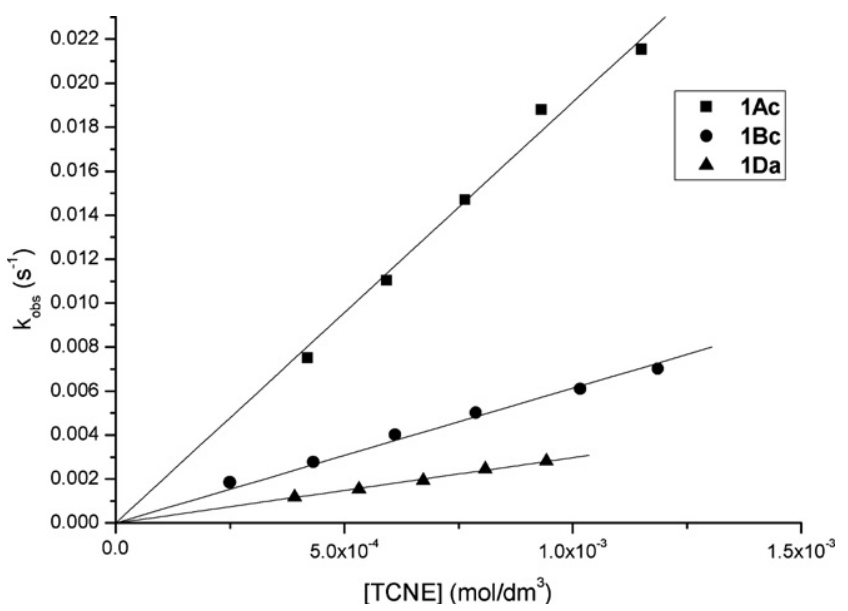

Fig. 1. Linear regression of the observed rate constants related to the first stage of the reactions of the complexes $1 \mathbf{A c}, \mathbf{1 B c}$ and 1Da with TCNE in $\mathrm{CHCl}_{3}$ at $298 \mathrm{~K}$. that allows an efficient electrophilic attack by the electron poor olefin TCNE. On the basis of its peculiar reactivity (see Table 1), the most promising substrate for determining the intermediate structure is the 1Da species. Analysis of the rate constants suggests fast accumulation of an intermediate which slowly leads to the reaction product. As a matter of fact, the first step displays a first order dependence on TCNE concentration, while the second stage involves a concentration independent monomolecular rearrangement. Apparently, the peculiar structure of the NEOC moiety does stabilize the intermediate which collapses slowly allowing the determination of its structure by low temperature ${ }^{1} \mathrm{H}$ NMR technique (Fig. 2). The aliphatic part of the ${ }^{1} \mathrm{H}$ NMR spectrum of complex 1Da recorded at $223 \mathrm{~K}$ is characterized by two sharp singlets of equal intensity at 2.93 and $3.40 \mathrm{ppm}$ ascribable to the $\mathrm{CH}_{3}$ protons of the ligand NEOC $(6 \mathrm{H})$ and to the $\mathrm{COOCH}_{3}$ protons $(6 \mathrm{H})$ of the palladacycle ring, respectively (Fig. 2a). As can be seen in Fig. 2b a remarkable splitting of the methyl signals is suddenly observed upon addition of a slight stoichiometric excess (2.2:1) of TCNE. In particular the singlet at $2.93 \mathrm{ppm}$ splits into two singlets at 1.03 and $3.17 \mathrm{ppm}$. The singlet at $3.40 \mathrm{ppm}$ undergoes a downfield shift with concomitant splitting into 3.92 and $4.07 \mathrm{ppm}$.

We suggest that this structural rearrangement is due to the formation of an unsymmetrical intermediate (type B) whose structure is represented in Chart 3:

The marked upfield shift of the singlet from 2.93 to $1.03 \mathrm{ppm}$ is probably due to the shielding exerted by the triple bonds of the two $\mathrm{CN}$ groups on the methyl protons of the neocuproine. The low temperature NOESY spectrum (Fig. 3) confirms such a hypothesis since only one methyl group of the neocuproine moiety $(3.17 \mathrm{ppm})$ is spatially correlated to one methyl group of the esteric fragment (4.07 ppm) (the NOESY spectrum of the starting complex in Supplementary material).

The singlet at $4.23 \mathrm{ppm}$ is finally ascribable to the esteric methyl protons of the fluoranthene-like cycle $\mathbf{2 a}$ [2], while the signal ascribable to the methyl group of the neocuproine fragment of the almost insoluble palladium( 0 ) complex 3D (which mostly precipitates) appears as a singlet of reduced intensity at $3.22 \mathrm{ppm}$. These signals firstly appear in the spectrum (b) of Fig. 2 as a consequence of the RT addition of TCNE to the cooled solution of starting complex. The formation of the reaction products is soon stopped on dropping the temperature to $223 \mathrm{~K}$. Spectrum (c) in Fig. 2 witnesses the completeness of the reaction. 


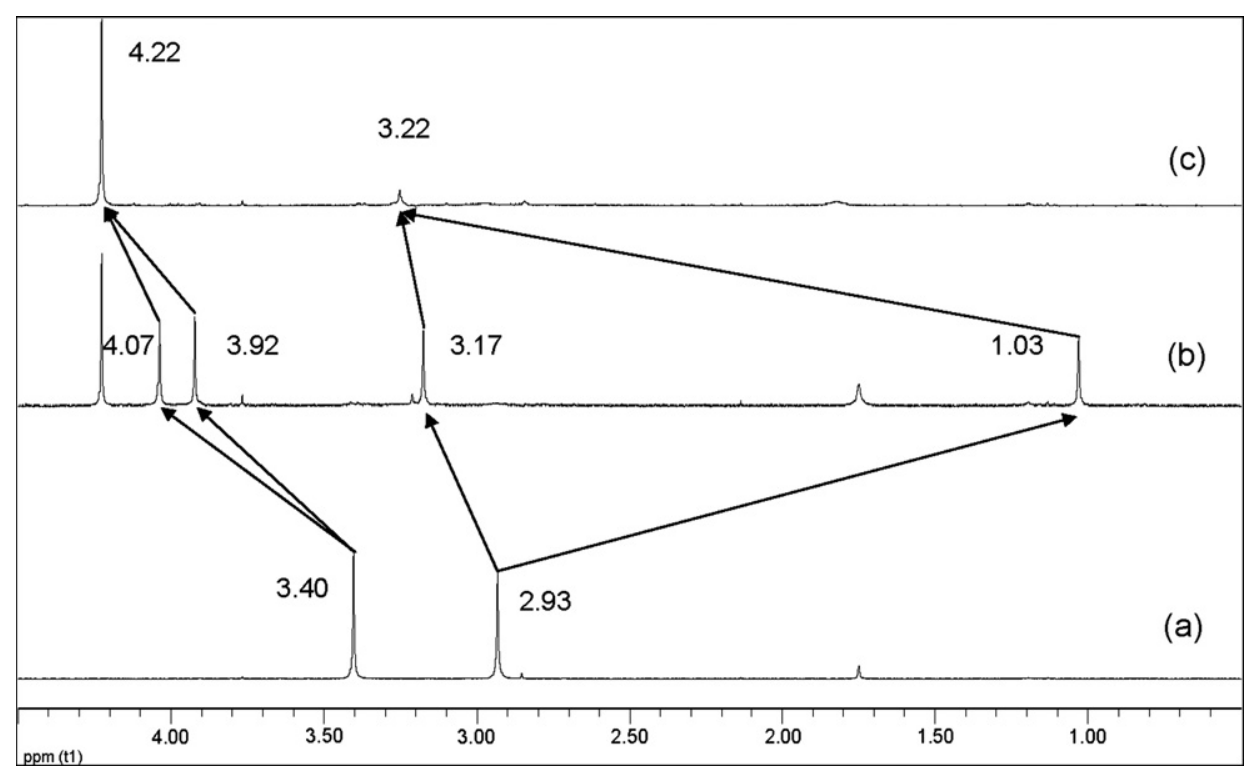

Fig. 2. Aliphatic part of the ${ }^{1} \mathrm{H}$ NMR spectra in $\mathrm{CDCl}_{3}$ at $223 \mathrm{~K}$ of the complex 1Da (a), of the complex 1Da after addition of TCNE (b) and of the reaction product $2 \mathrm{a}(\mathrm{c})$.

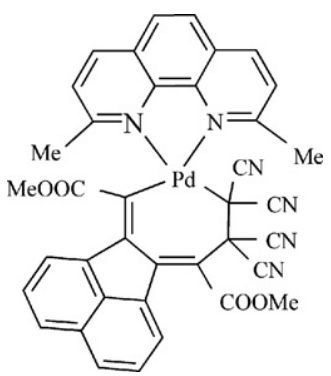

Chart 3.

It is noteworthy that despite the steric hindrance exerted by the methyl substituents at the NEOC rings no Diels-Alder intermediate (type $\mathbf{A}$ ) is formed. We therefore advance the hypothesis that when metallacycle dienes carrying electron withdrawing groups are involved, intermediates of type $\mathbf{B}$ are preferred even when a remarkable steric hindrance seems to suggest an axial attack of the alkyne with subsequent formation of a type A intermediate. Apparently the LUMO orbitals of the unsaturated cycle under the action of the withdrawing groups are not energetically prone to attack by the strongly activated alkyne and consequently the alternative mechanism based on the formation of the hepta-membered cycle becomes preferred.

From the data in Table 1, it is apparent that the complex $\left[\mathrm{Pd}\left(\mathrm{C}_{4}(\mathrm{COOMe})_{4}\right)(\mathrm{NEOC})\right](1 \mathrm{Dc})$ would enhance the possibility of structural investigation due to its synergic steric and electronic characteristics in lowering both the reaction rates. Unfortunately, any attempt to synthesize such a complex was unsuccessful. In fact, as can be seen in the Supplementary Material the palladacyclopentadienyl complexes with NEOC as ancillary ligand can be obtained only by the attack of the alkyne 1,8-bis(methylpropynoate)naphthalene on the palladium $(0)$ derivative $\left[\operatorname{Pd}\left(\eta^{2}-\right.\right.$ $\mathrm{dmfu})(\mathrm{NEOC})](\mathrm{dmfu}=$ dimethylfumarate $)$. The ligand exchange approach [3p] starting from the complexes 1Ac or $1 \mathrm{Bc}$ and NEOC does not produce the complex owing to the low tendency of NEOC to coordination. The direct synthesis as suggested by Elsevier based on the reaction of $\mathrm{Pd}_{2} \mathrm{DBA}_{3}$ with DMA and NEOC [7] does not work either. On the other hand, the direct attack of dimethylacetylene dicarboxylate (DMA) on [Pd( $\eta^{2}$-dmfu)(NEOC)] induces the formation of the stable species $\left[\operatorname{Pd}\left(\eta^{2}\right.\right.$-DMA)(NEOC)], as would be expected of a $\operatorname{Pd}(0)$ alkyne complex stabilized by the bulkiness of the ancillary ligand according to tom Dieck's and our own findings [3b,1a].

Incidentally, with the aim of obtaining the value of the equilibrium constant for the exchange reaction between alkenes and alkynes in palladium $(0)$ complex (since the direct exchange between the dmfu in the complex $\left[\operatorname{Pd}\left(\eta^{2}\right.\right.$ dmfu)(NEOC)] and DMA was complicated by decomposition), we studied the following reaction in $\mathrm{CHCl}_{3}$ at $25^{\circ} \mathrm{C}$ $(\mathrm{fn}=$ fumaronitrile):

$$
\begin{aligned}
& {\left[\operatorname{Pd}\left(\eta^{2}-\mathrm{fn}\right)(\mathrm{NEOC})\right]+\text { DMA }} \\
& \quad \leftrightarrow\left[\operatorname{Pd}\left(\eta^{2}-\mathrm{DMA}\right)(\mathrm{NEOC})\right]+\mathrm{fn}
\end{aligned}
$$

The titration was carried out by recording the UV/Vis spectra in the interval $300-500 \mathrm{~nm}$ of solutions obtained by addition of microaliquots of a concentrated solution of DMA to a $1 \times 10^{-4} \mathrm{~mol} \mathrm{dm}^{-3}$ solution of the complex under study. The equilibrium constant calculated at $410 \mathrm{~nm}$ was $K_{\mathrm{E}(\mathrm{fn} / \mathrm{DMA})}=0.0122 \pm 0.0006$ (Fig. 4) and at the best of our knowledge this result represents the second example of a published equilibrium constant dealing with the exchange between alkenes and alkynes in palladium $(0)$ complexes. However this case is the first detected one in the presence of only the reactants and products since no complication due to secondary or subsequent reactions will interfere. 


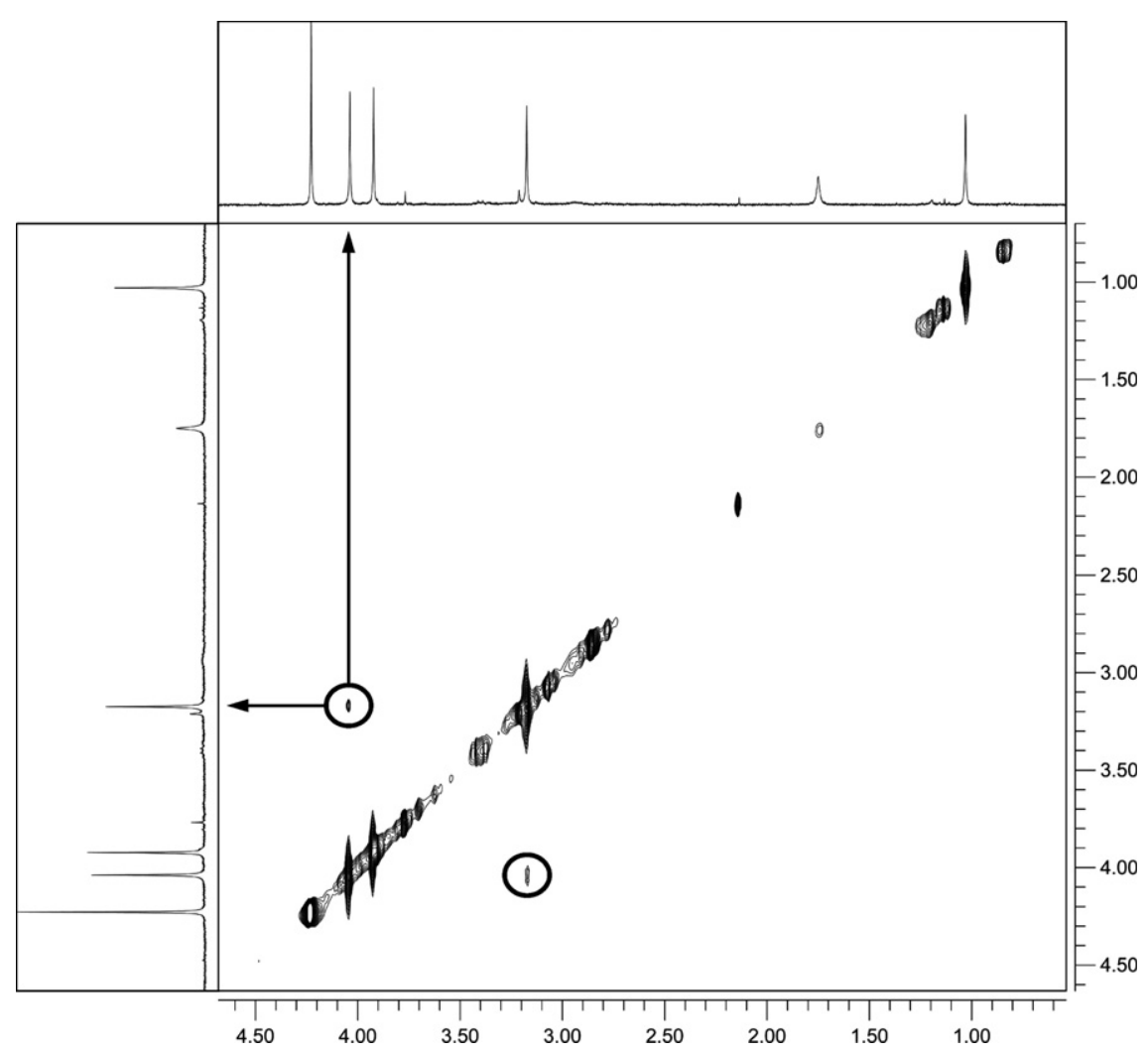

Fig. 3. NOESY spectrum of complex 1Da after addition of TCNE in $\mathrm{CDCl}_{3}$ at $223 \mathrm{~K}$.

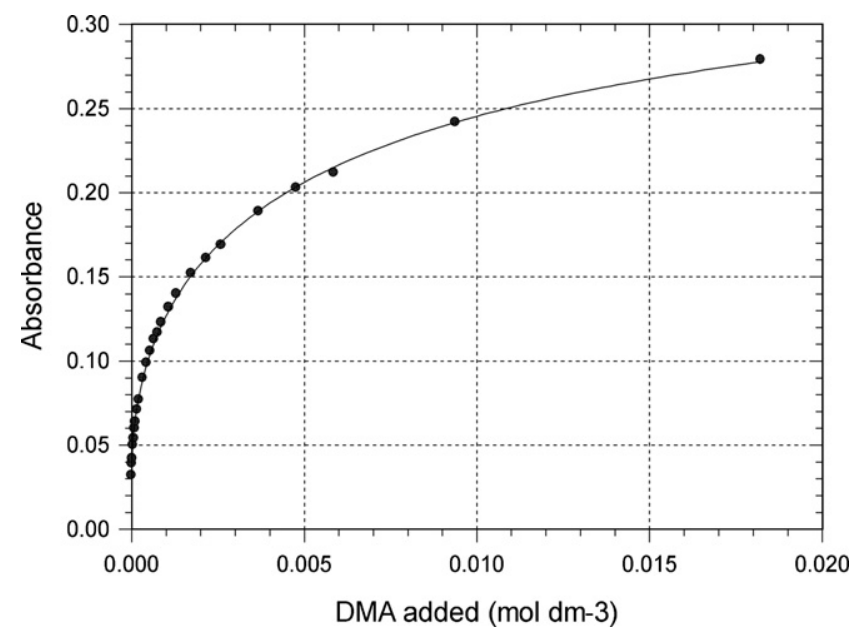

Fig. 4. Non linear regression analysis for the spectrophotometric titration of the complex $\left[\mathrm{Pd}\left(\eta^{2}-\mathrm{fn}\right)(\mathrm{NEOC})\right]\left(\mathbf{3}^{\prime} \mathbf{D}\right)$ with DMA in $\mathrm{CHCl}_{3}$ at $298 \mathrm{~K}$.

The first equilibrium constant determined so far was related to the exchange between the complex $\left[\operatorname{Pd}\left(\eta^{2}-\right.\right.$ $\mathrm{ma})(\mathrm{MeNS} t \mathrm{Bu})](\mathrm{ma}=$ maleic anhydride, $\mathrm{MeNS} t \mathrm{Bu}=2-$ (methyl-thio-tbutyl) pyridine) and DMA [1a]. An exchange equilibrium constant $K_{\mathrm{E}(\mathrm{ma} / \mathrm{DMA})}=0.0140 \pm 0.003$ was measured, this value not surprisingly being very similar to that determined in the present work. These values are in agreement with the order of olefin coordinative ability determined so far for $\operatorname{Pd}(0)$ complexes [8]. In this respect, it is noteworthy that also the ligand $\mathrm{MeNStBu}$ has an important steric influence and holds a methyl group pointing toward the metal centre, thus displaying a marked similarity with the NEOC ligand. However, at variance with NEOC, the steric hindrance of MeNStBu does not completely hamper the subsequent reaction yielding the palladacyclopentadienyl derivative [1a]. On the basis of the cited olefin coordination order [8a] it is also possible to estimate a rough value for the equilibrium constant in the case of the reaction between $\left[\operatorname{Pd}\left(\eta^{2}-\mathrm{dmfu}\right)(\mathrm{NEOC})\right]$ and DMA. The ensuing value $\left(K_{\mathrm{E}(\mathrm{dmfu} / \mathrm{DMA})} \approx 60\right)$ agrees with the complete displacement of dmfu and the concomitant quantitative formation of the complex $\left[\operatorname{Pd}\left(\eta^{2}\right.\right.$-DMA $\left.)(\mathrm{NEOC})\right]$ under preparative conditions. Apparently, the steric hindrance exerted by the methyl groups of the NEOC moiety strongly destabilizes the $\operatorname{Pd}(0)$ DMA derivative probably owing to the interferences between the methyl groups of NEOC and of DMA lying in the same main molecular plane but at the same time it hinders any further DMA attack or other bimolecular rearrangements preventing the formation of the metallacyclopentadienyl derivative.

\section{Appendix A. Supplementary materials}

Data on the synthesis and characterization of the novel chemical derivatives, kinetics and calculation details. Supplementary data associated with this article can be found, in the online version, at doi:10.1016/j.jorganchem.2007.06.037. 


\section{References}

[1] (a) L. Canovese, F. Visentin, G. Chessa, P. Uguagliati, C. Levi, A. Dolmella, Organometalllics 24 (2005) 5537;

(b) L. Canovese, F. Visentin, G. Chessa, C. Santo, C. Levi, P. Uguagliati, Inorg. Chem. Com. 9 (2006) 388.

[2] L. Canovese, F. Visentin, G. Chessa, P. Uguagliati, C. Santo, L. Maini, J. Organomet. Chem. 692 (2007) 2342.

[3] (a) N.E. Schore, Chem. Rev. 88 (1988) 1081;

(b) H. Tom Dieck, C. Munz, C. Mueller, J. Organomet. Chem. 384 (1990) 243;

(c) S. Cacchi, J. Organomet. Chem. 576 (1999) 42;

(d) M. Rubin, A.W. Sromek, Gevorgyan V. Synlett. 15 (2003) 2265;

(e) R. van Belzen, H. Hoffmann, C.J. Elsevier, Angew. Chem., Int. Ed. Eng. 36 (1997) 1743;

(f) R. van Belzen, R.A. Klein, H. Kooijman, N. Veldman, A.L. Spek, C.J. Elsevier, Organometallics 17 (1998) 1812;

(g) R. van Belzen, C.J. Elsevier, A. Dedieu, N. Veldman, A.L. Spek, Organometallics 22 (2003) 722;

(h) B.M. Trost, G.J. Tanoury, J. Am. Chem. Soc. 109 (1987) 4753;

(i) B.M. Trost, G.J. Tanoury, J. Am. Chem. Soc. 110 (1988) 1636;

(j) B.M. Trost, M.K. Trost, J. Am. Chem. Soc. 113 (1991) 1850;

(k) B.M. Trost, S.K. Hashmi, J. Am. Chem. Soc. 116 (1994) 2183;

(1) H. Suzuki, K. Itoh, Y. Ishii, K. Simon, J.A. Ibers, J. Am. Chem. Soc. 98 (1976) 8494;

(m) C.M. Crawforth, I.J.S. Fairlamb, A.R. Kapdi, J.L. Serrano, R.J.K. Taylor, G. Sanchez, Adv. Synth. Cat. 348 (2006) 406; (n) J.L. Serrano, I.J.S. Fairlamb, G. Sanchez, L. Garcia, J. Perez, J. Vives, G. Lopez, C.M. Crawforth, R.J.K. Taylor, Eur. J. Inorg. Chem. 13 (2004) 2706;

(o) K. Moseley, P.M. Maitlis, J. Chem. Soc., Dalton Trans. (1974) 109 ;

(p) L. Canovese, F. Visentin, G. Chessa, P. Uguagliati, C. Santo, A. Dolmella, Organometalllics 24 (2005) 3308.

[4] (a) A.M. Ferrari, L. Giordani, G. Pacchioni, S. Abbet, U. Heiz, J. Phys. Chem. 106 (2002) 3173;

(b) A.M. Ferrari, L. Giordani, N. Rösch, U. Heiz, S. Abbet, A. Sanchez, G. Pacchioni, J. Phys. Chem. 104 (2000) 10612.

[5] S. Saito, Y. Yamamoto, Chem. Rev. 100 (2000) 2901, and refs. therein.

[6] (a) F.E. McDonald, H.Y.H. Zhu, C.R. Holmquist, J. Am. Chem. Soc. 117 (1995) 6605;

(b) K. Mach, S.I. Troyanov, J. Organomet. Chem. 414 (1991) C15;

(c) M. Scozzafava, A.M. Stolzemberg, Organometallics 7 (1988) 1073;

(d) M. Kotora, C. Umeda, T. Ishida, T. Takahashi, Tetrahedron Lett. 38 (1997) 8355;

(e) E. Alvarez, M. Paneque, M.L. Povera, N. Rendón, Angew. Chem. Int. Ed. 45 (2006) 474, and refs. therein.

[7] A. Holuigue, C. Sirlin, M. Pfeffer, K. Goubitz, J. Fraanje, C.J. Elsevier, Inorg. Chim. Acta 359 (2006) 1773.

[8] (a) L. Canovese, F. Visentin, P. Uguagliati, B. Crociati, J. Chem. Soc., Dalton Trans. 1921 (1996);

(b) L. Canovese, F. Visentin, G. Chessa, P. Uguagliati, A Dolmella, J. Organomet. Chem. 601 (2000) 1. 